\title{
Analisis Pengaruh Lingkungan Kerja Terhadap Produktivitas Pekerja
}

\author{
M W Wardana ${ }^{1}$, Ergantara R $\mathbf{I}^{2}$ \\ ${ }^{1)}$ Fakultas Teknik, Program Studi Teknik Industri, Universitas Malahayati \\ Jl. Pramuka No. 27, Kemiling Bandarlampung \\ Email : marcelly@malahayati.ac.id \\ ${ }^{2)}$ Fakultas Teknik, Program Studi Teknik Lingkungan, Universitas Malahayati \\ Jl. Pramuka No. 27, Kemiling Bandarlampung \\ Email : ergantararani@yahoo.com
}

\begin{abstract}
ABSTRAK
Banyak hal yang mempengaruhi produktivitas diantaranya adalah pengaruh suhu udara dan kelembaban udara lingkungan kerja. Penelitian ini bertujuan untuk mengetahui pengaruh lingkungan kerja terhadap produktivitas pekerja. Sampel dalam penelitian ini adalah pekerja genteng pada bagian produksi (pengepresan) genteng dan finishin pada pabrik genteng yang ada di Kabupaten Pringsewu pada 4 Kecamatan yaitu Kecamatan Pringsewu, Kecamatan Ambarawa, Kecamatan Gadingrejo dan Kecamatan Sukoharjo, data sampel akan dianalisis menggunakan uji Paired Sample T-Test menggunakan software SPSS. Berdasarkan hasil perhitungan menggunakan SPSS untuk variable suhu diperoleh hasil adalah nilai t hitung sebesar 13,403 > t tabel 2,032 dan nilai Sig. sebesar 0,000<0,05, dan pada variable kelembaban nilai $-\mathrm{t}$ hitung sebesar $-13,403<-t$ tabel $-2,032$ dan nilai Sig. 0,000 < 0,05. Sehingga H0 ditolak dan menerima H1, bahwa adanya pengaruh antara suhu dan kelembaban udara dengan produktivitas pekerja. Dengan demikian untuk menjafa hasil produksi agar terus maksimal sebaiknya tingkat suhu lingkungan kerja harus berada di suhu yang sejuk (suhu rendah) dan tingkat kelembaban udara pada tingkat kelembaban yang tinggi.
\end{abstract}

Kata kunci : Produktivitas, Suhu Udara, Kelembaban Udara, Paired T-Test

\begin{abstract}
Many things that affect productivity include the influence of air temperature and humidity in the work environment. This study aims to determine the effect of the work environment on worker productivity. The samples in this study were tile workers in the production (pressing) section of tile and finishing at tile factories in Kabupaten Pringsewu in 4 Kecamatan namely Kecamatan Pringsewu,Kecamatan Ambarawa, Kecamatan Gadingrejo and Kecamtan Sukoharjo, sample data will be analyzed using the Paired Sample TTest Test using SPSS software. Based on the results of calculations using SPSS for temperature variables, the results obtained are the $t$ value of 13.403>t table 2.032 and Sig. equal to 0,000<0.05, and the humidity variable value of -t count of $-13.403<-t$ table -2.032 and Sig. 0,000<0.05. So HO is rejected and accepts H1, that there is an influence between temperature and humidity of the air with worker productivity. Thus to ensure that production results continue to be maximal the level of temperature in the working environment must be at a cool temperature (low temperature) and the level of humidity in the air at high humidity levels.
\end{abstract}

\section{Keywords : Productivity, Work Environment, Paired T-Test}

\section{PENDAHULUAN}

Lingkungan kerja merupakan salah satu hal yang mempengaruhi produktivitas, Wignjosoebroto et al [1] , sedangkan menurut Nurulloh [2] lingkungan kerja dapat mempengaruhi produktivitas pekerja, dimana lingkungan kerja fisik lebih berpengaruh terhadap produktivitas pekerja apabila dibandingkan dengan lingkungan kerja non fisik. Sedangkan menurut Geng et al.,[3] ada pengaruh dari suhu lingkungan kerja terhadap produktivitas pekerja. Hal ini dibuktikan dari beberapa penilitan yang telah dilakukan antara lain Mahamahit [4] hasil yang didapatkan adalah adanya pengaruh kelembaban dan suhu ruangan terhadap produktivitas. Penelitian yang dilakukan oleh Tsutsumi [5] mendapatkan bahwa kondisi kelembaban udara yang baik untuk menjaga produktivitas adalah sebesar 30\% - 50\%, dan produktivitas pekerja menurun pada kelembaban udara sebesar 70\%. Penelitian lain dilakukan oleh Purnomo [6] didapatkan bahwa dengan suhu dibawah $22^{\circ} \mathrm{C}$ dengan berapapun tingkat kelembaban udara maka produktivitas pekerja tetap terjaga, 
sedangkan kondisi optimal dalah pada suhu udara sebesar $27^{\circ} \mathrm{C}$ dengan tingkat kelembaban udara sebesar $40 \%$.

Penelitian dilaksanakan di Kabupaten Pringsewu yang merupakan penghasil genteng tanah liat (genteng press) di Provinsi Lampung, Kabupaten Pringsewu ini mempunyai rata-rata suhu udara $30^{\circ} \mathrm{C}$ dan kelembaban udara berkisar 85\%, BPS [7]. Dengan kondisi lingkungan kerja tersebut masih dikatakan belum ideal, yang mengakibatkan pekerja sering merasa cepat lelah, berdasarkan Keputusan Menteri Kesehatan [8] lingkungan kerja yang ideal berada pada kondisi suhu (18-28) ${ }^{\circ} \mathrm{C}$ dan kelembaban udara (40-60)\%.

Penelitian ini bertujuan untu menganalisis pengaruh lingkungan kerja dengan variable suhu dan kelembaban udara terhadap produktivitas pekerja. Hasil dari penelitian ini diharapkan dapat menjadi rujukan bagi pemilik perusahaan untuk memperbaiki lingkungan kerja untuk mendapatkan lingkungan kerja yang ideal.

\section{METODE PENELITIAN}

Penelitian ini mengambil sampel pada pekerja genteng press pada 5 perusahaan yang berbeda di empat kecamatan. Yaitu Kecamatan Pringsewu, Kecamatan Ambarawa, Kecamatan Gading Rejo dan Kecamatan Sukoharjo pada bagian pengepresan dan finishing, data diambil pada dua waktu, yaitu pada pagi hari dan pada siang hari. Hal ini dilakukan karena terdapat perbedaan yang signifikan keadaan lingkungan kerja baik suhu udara dan kelembaban lingkungan kerja pada pagi dan siang hari.

Variabel yang diamati pada penelitian ini adalah : Tingkat Suhu Udara, Kelembaban Udara dan Hasil Produksi Genteng.

Untuk menganalisa data penelitian yang telah diperoleh menggunakan Uji Paired Sample T-Test, dikarenakan sample yang akan diuji berasal dari subjek yang sama namun diambil pada keadaan yang berbeda.

Hipotesa awal dari penelitian ini adalah :

$\mathrm{H} 0$ = Tidak ada pengaruh lingkungan kerja terhadap produktivitas pekerja

H1 = Adanya pengaruh lingkungan kerja terhadap produktivitas pekerja.

\section{HASIL DAN PEMBAHASAN}

Hasil data yang diperoleh dari penelitian ini adalah sebagai berikut :

Tabel 1. Data Penelitian

\begin{tabular}{|c|c|c|}
\hline \multirow{2}{*}{ No } & \multicolumn{2}{|c|}{ Produksi Genteng } \\
\hline & Pagi & Siang \\
\hline 1 & 460 & 427 \\
\hline 2 & 480 & 442 \\
\hline 3 & 472 & 454 \\
\hline 4 & 462 & 451 \\
\hline 5 & 483 & 444 \\
\hline 6 & 480 & 452 \\
\hline 7 & 483 & 420 \\
\hline 8 & 467 & 431 \\
\hline 9 & 481 & 447 \\
\hline 10 & 477 & 459 \\
\hline 11 & 467 & 457 \\
\hline 12 & 483 & 451 \\
\hline 13 & 485 & 459 \\
\hline 14 & 481 & 425 \\
\hline 15 & 459 & 423 \\
\hline 16 & 473 & 439 \\
\hline 17 & 469 & 451 \\
\hline 18 & 459 & 449 \\
\hline 19 & 475 & 443 \\
\hline 20 & 477 & 451 \\
\hline 21 & 473 & 417 \\
\hline
\end{tabular}




\begin{tabular}{|l|c|c|}
\hline 22 & 458 & 422 \\
\hline
\end{tabular}

Tabel 1. Data Penelitian (lanjutan)

\begin{tabular}{|c|c|c|}
\hline \multirow{2}{*}{ No } & \multicolumn{2}{|c|}{ Produksi Genteng } \\
\cline { 2 - 3 } & Pagi & Siang \\
\hline 23 & 472 & 438 \\
\hline 24 & 468 & 450 \\
\hline 25 & 458 & 448 \\
\hline 26 & 474 & 442 \\
\hline 27 & 476 & 450 \\
\hline 28 & 472 & 416 \\
\hline 29 & 468 & 420 \\
\hline 30 & 464 & 434 \\
\hline 31 & 468 & 452 \\
\hline 32 & 472 & 438 \\
\hline 33 & 462 & 426 \\
\hline 34 & 476 & 442 \\
\hline 35 & 472 & 454 \\
\hline
\end{tabular}

Tabel diatas adalah data hasil penelitian, penelitian diambil pada 2 waktu yang berbeda yaitu pada pagi hari dengan suhu udara rendah dan kelembaban tinggi, kemudian waktu yang kedua adalah siang hari pada saat suhu udara tinggi dan kelembaban udara rendah.

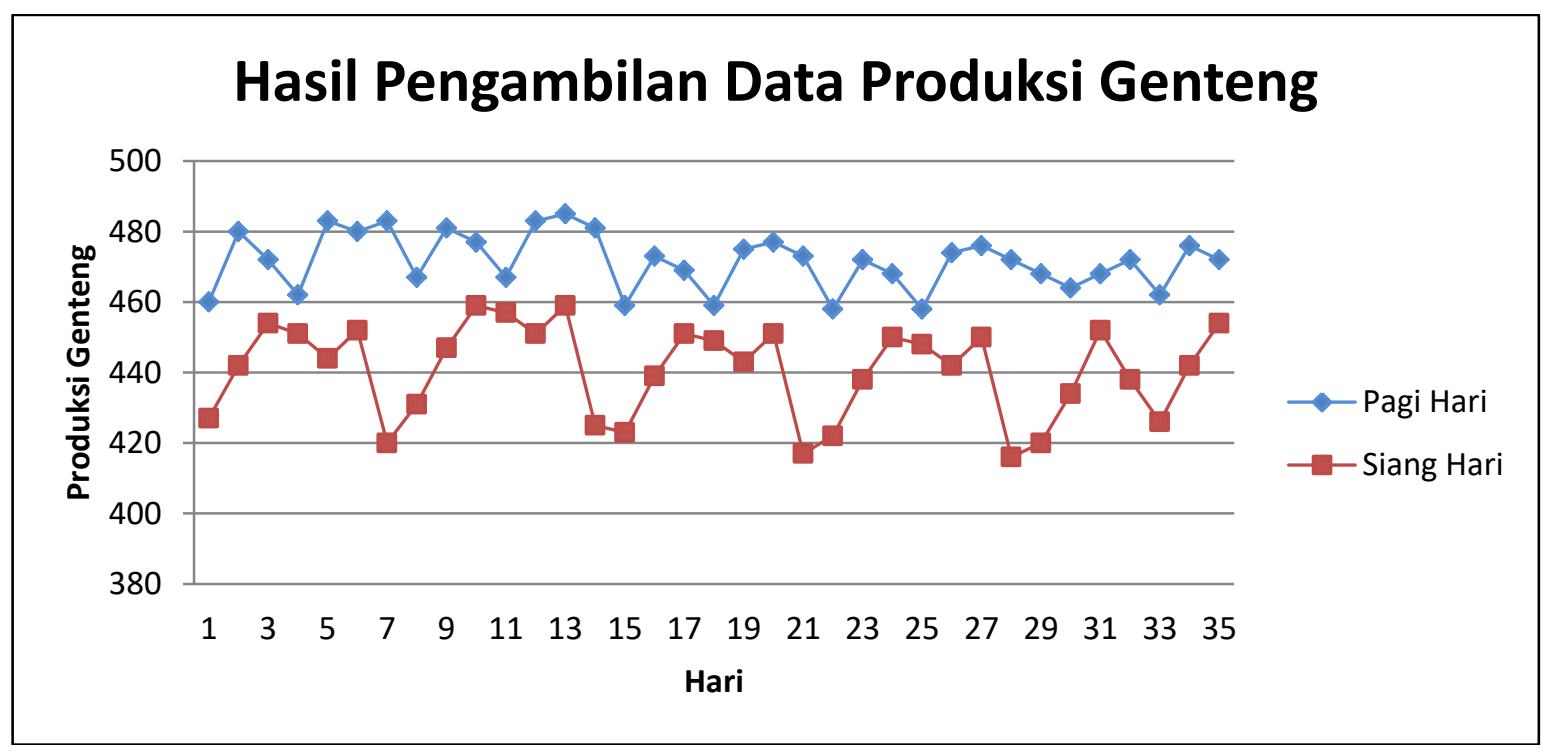

Gambar 1. Grafik data hasil penelitian

Berdasarkan data diatas dapat dilihat bahwa pada pagi hari genteng yang dihasilkan dari proses press lebih banyak apabila dibandingkan pada waktu siang hari.

Dari data tersebut dilakukan uji untuk mengetahui pengaruh lingkungan kerja terhadap produktivitas pekerja menggunakan Paired Sample T-Test. Hasil dari uji tersebut adalah sebagai berikut. Hasil Analisa Data Variabel Suhu menggunakan uji Paired Sample T-Test

Paired Samples Statistics

\begin{tabular}{|l|r|r|r|r|}
\hline & Mean & N & Std. Deviation & Std. Error Mean \\
\hline Pair 1 Suhu Rendah & 471.60 & 35 & 7.968 & 1.347 \\
\hline
\end{tabular}




\begin{tabular}{|l|r|r|r|r|}
\hline \multicolumn{1}{|c|}{ Suhu Tinggi } & 440.69 & 35 & 13.087 & \\
\hline \multicolumn{6}{|c|}{ Paired Samples Correlations } \\
\hline & & $\mathrm{N}$ & Correlation & Sig. \\
\hline Pair 1 & Suhu Rendah \& Suhu Tinggi & 35 & .233 & .178 \\
\hline
\end{tabular}

\section{Paired Samples Test}

\begin{tabular}{|c|c|c|c|c|c|c|c|c|c|}
\hline & & \multicolumn{5}{|c|}{ Paired Differences } & \multirow[t]{3}{*}{$\mathrm{t}$} & \multirow[t]{3}{*}{$\mathrm{df}$} & \multirow{3}{*}{$\begin{array}{l}\text { Sig. (2- } \\
\text { tailed) }\end{array}$} \\
\hline & & \multirow[t]{2}{*}{ Mean } & \multirow[t]{2}{*}{$\begin{array}{c}\text { Std. } \\
\text { Deviation }\end{array}$} & \multirow[t]{2}{*}{$\begin{array}{c}\text { Std. Error } \\
\text { Mean }\end{array}$} & \multicolumn{2}{|c|}{$\begin{array}{c}95 \% \text { Confidence } \\
\text { Interval of the } \\
\text { Difference } \\
\end{array}$} & & & \\
\hline & & & & & Lower & Upper & & & \\
\hline $\begin{array}{l}\text { Pair } \\
1\end{array}$ & $\begin{array}{l}\text { Suhu Rendah - Suhu } \\
\text { Tinggi }\end{array}$ & 30.914 & 13.645 & 2.307 & 26.227 & 35.602 & 13.403 & 34 & .000 \\
\hline
\end{tabular}

Gambar 2. Hasil Uji Paired T-Test pada variabel suhu menggunakan SPSS

Berikut ini adalah hasil analisa data variabel kelembaban menggunakan Paired Sample T-Test

\begin{tabular}{|c|c|c|c|c|c|}
\hline \multicolumn{6}{|c|}{ Paired Samples Statistics } \\
\hline & & Mean & $\mathrm{N}$ & Std. Deviation & Std. Error Mean \\
\hline \multirow{2}{*}{ Pair 1} & Kelembaban Rendah & 440.69 & 35 & 13.087 & 2.212 \\
\hline & Kelembaban Tinggi & 471.60 & 35 & 7.968 & 1.347 \\
\hline
\end{tabular}

Paired Samples Correlations

\begin{tabular}{|rl|r|r|r|}
\hline & \multicolumn{1}{|c|}{$\mathrm{N}$} & \multicolumn{1}{c|}{ Correlation } & \multicolumn{1}{c|}{ Sig. } \\
\hline \multirow{2}{*}{ Pair 1 } & $\begin{array}{l}\text { Kelembaban Rendah \& } \\
\text { Kelembaban Tinggi }\end{array}$ & 35 & .233 & .178 \\
\hline
\end{tabular}

\begin{tabular}{|c|c|c|c|c|c|c|c|c|c|}
\hline \multicolumn{10}{|c|}{ Paired Samples Test } \\
\hline & & \multicolumn{5}{|c|}{ Paired Differences } & \multirow[t]{3}{*}{$\mathrm{t}$} & \multirow[t]{3}{*}{ df } & \multirow{3}{*}{$\begin{array}{l}\text { Sig. }(2- \\
\text { tailed) }\end{array}$} \\
\hline & & \multirow[t]{2}{*}{ Mean } & \multirow[t]{2}{*}{$\begin{array}{c}\text { Std. } \\
\text { Deviation }\end{array}$} & \multirow[t]{2}{*}{$\begin{array}{l}\text { Std. Error } \\
\text { Mean }\end{array}$} & \multicolumn{2}{|c|}{$\begin{array}{c}\text { 95\% Confidence } \\
\text { Interval of the } \\
\text { Difference }\end{array}$} & & & \\
\hline & & & & & Lower & Upper & & & \\
\hline $\begin{array}{l}\text { Pair } \\
1\end{array}$ & $\begin{array}{l}\text { Kelembaban Rendah } \\
\text { - Kelembaban Tinggi }\end{array}$ & $\begin{array}{r}- \\
30.914\end{array}$ & 13.645 & 2.307 & -35.602 & -26.227 & -13.403 & 34 & .000 \\
\hline
\end{tabular}

Gambar 3. Hasil Uji Paired T-Test pada variabel kelembaban menggunakan SPSS

Berdasarkan analisis data diatas kita dapat mengetahui bahwa:

1. Rata-rata produksi genteng pada suhu rendah lebih banyak bila dibandingkan produksi genteng pada suhu tinggi, hal ini berbanding terbalik dengan variabel kelembaban, dimana pada kelembaban udara tinggi produksi genteng lebih banyak dari pada pada saat kelembaban udara rendah. 
2. Berdasarkan output diatas dapat disimpulkan bahwa nilai korelasi antar variabel baik suhu udara maupun kelembaban udara sebesar 0,233 dengan nilai signifikansi (Sig.) sebesar 0,178. Karena nilai Sig. 0,178 > 0,05 maka dapat dikatakan bahwa tidak ada hubungan antara variabel suhu rendah dengan suhu tinggi maupun variabel kelembaban udara tinggi dengan kelembaban udara rendah.

3. Berdasarkan output diatas besarnya t hitung adalah 13,403 dan nilai Sig. 0,000. Karena nilai t-hitung 13,403 > t-tabel 2,032 untuk suhu udara, - t-hitung -13,403 < - t-tabel -2,032 dan nilai Sig. 0,000 $<0,05$ maka H0 ditolak dan menerima H1, sehingga dapat disimpulkan bahwa ada pengaruh lingkungan kerja terhadap produktivitas pekerja genteng press.

Dari hasil diatas didapatkan bahwa ada pengaruh lingkungan kerja dengan variabel suhu dan kelembaban udara dengan produktivitas kerja. Untuk menjaga agar produktivitas kerja pada suhu yang optimal maka dapat diambil beberapa solusi antara lain adalah mengubah layout pabrik antara lain adalah :

1. Meninggikan atap pabrik

2. Menambahkan rak-rak penjemuran genteng disekitar area pengepresan

3. Menambah pepohonan disekitar pabrik untuk menciptakan udara yang sejuk.

Berikut ini adalah beberapa gambar (desain) untuk perbaikan lay out pabrik

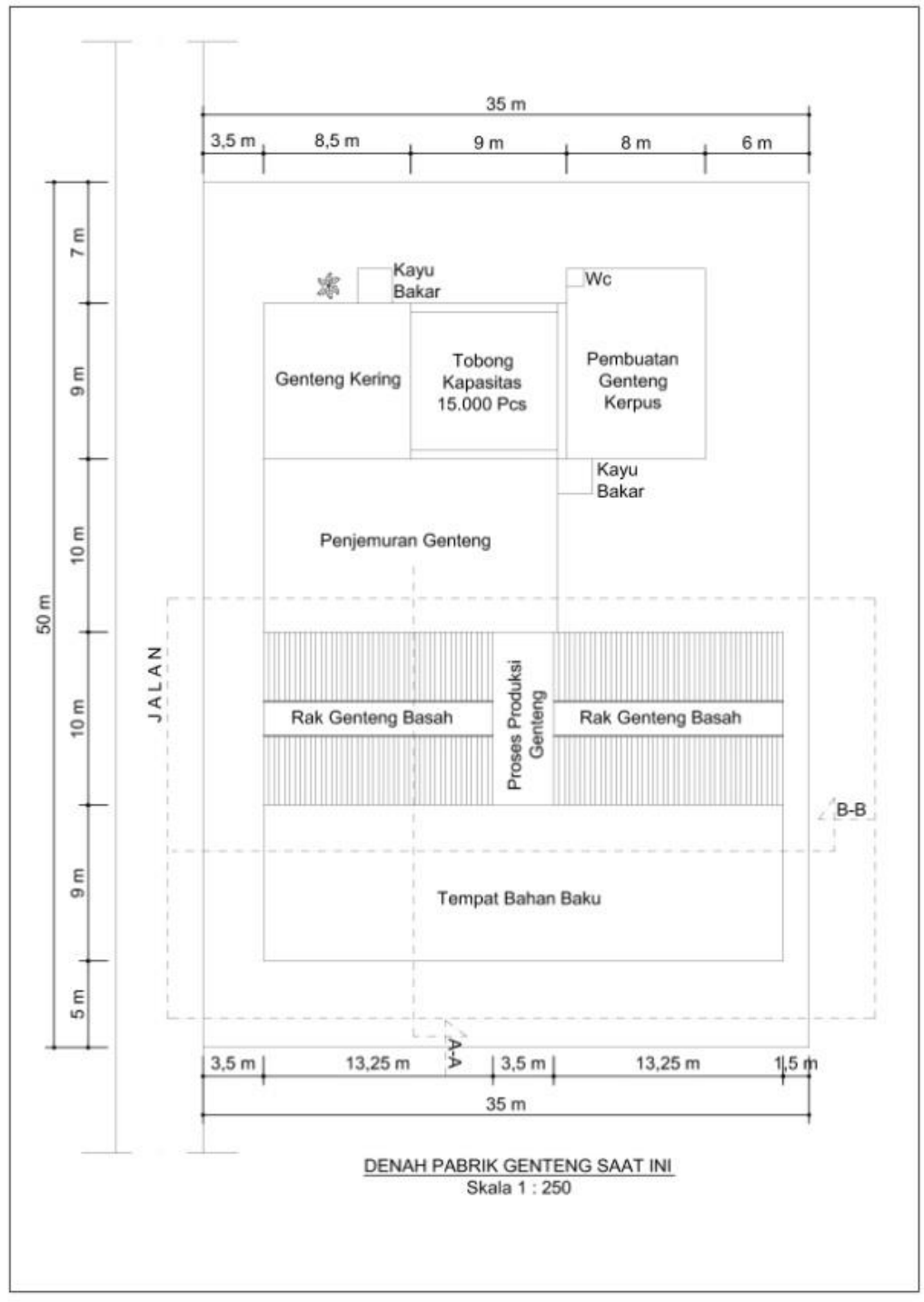

Gambar 4. Layout awal Pabrik 


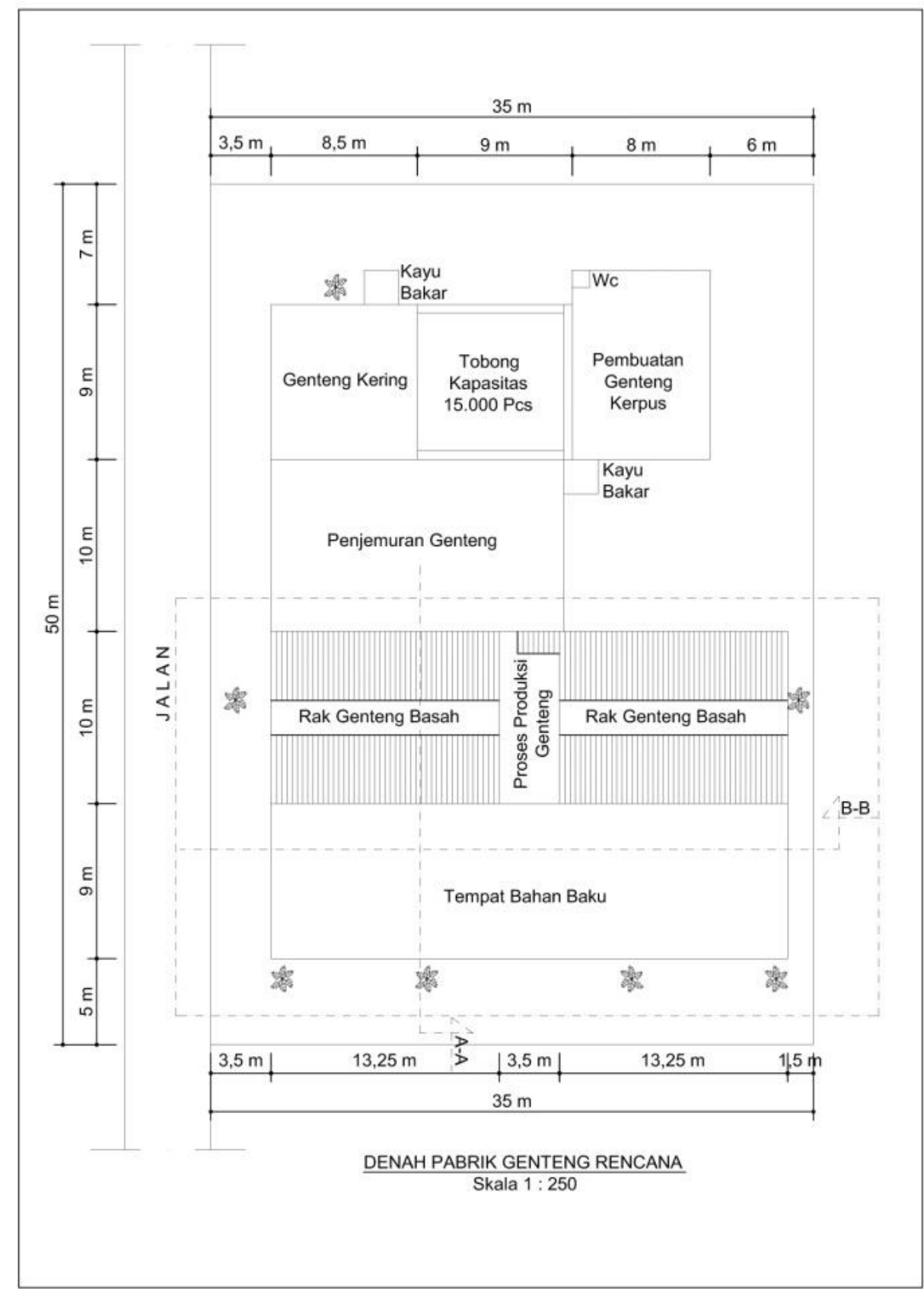

Gambar 5. Layout usulan penambahan pohon dan rak 


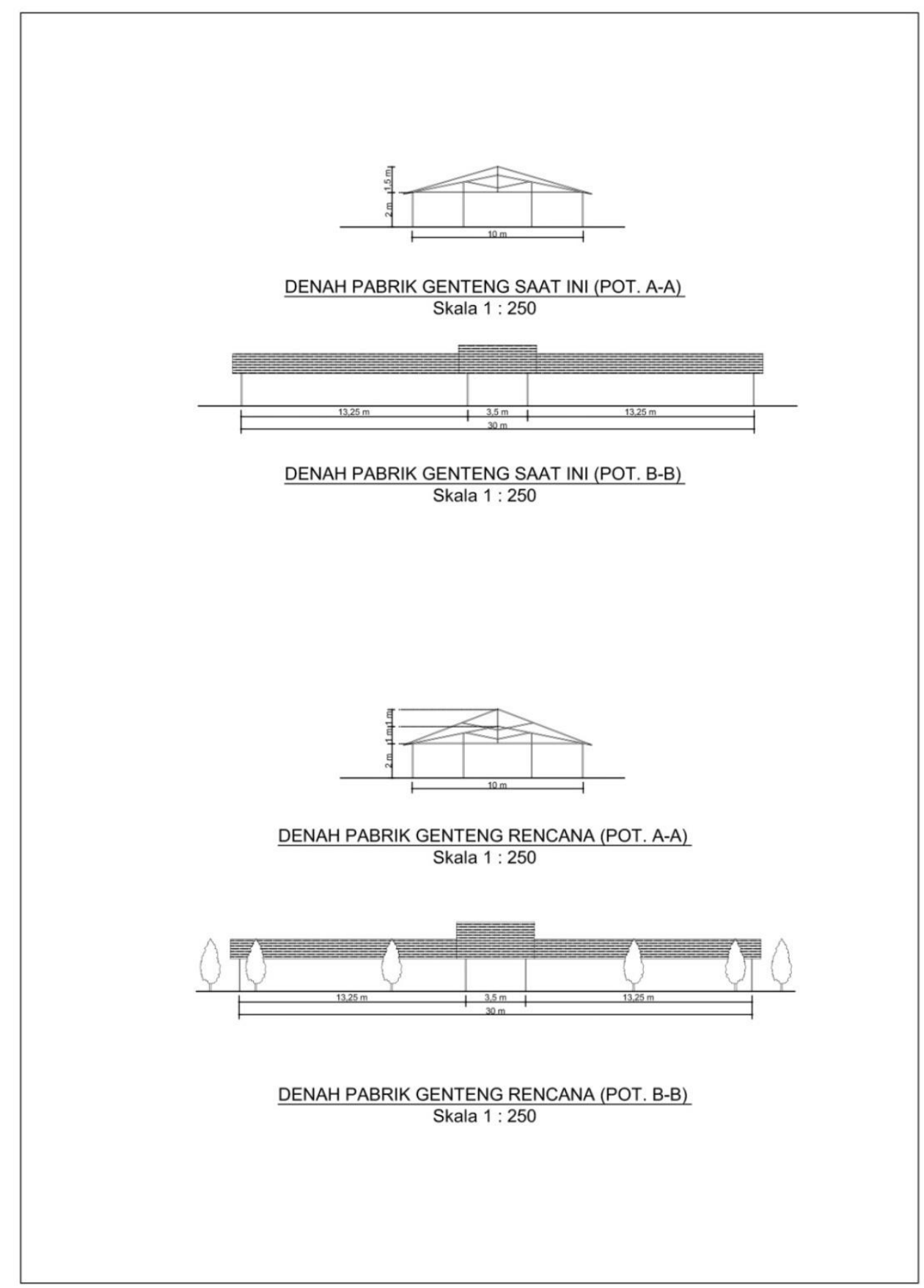

Gambar 6. Layout usulan penambahan tinggi atap

\section{SIMPULAN}

Berdasarkan hasil penelitian diatas dapat disimpulkan bahwa ada pengaruh antara lingkungan kerja terhadap produktivitas pekerja. Hal ini dapat dilihat dari hasil uji Paired Sample T-Test dimana hasil uji tersebut mempunyai nilai Sig. 0,000 yang artinya adalah penolakan H0 dan menerima H1 dimana ada Pengaruh Lingkungan Kerja terhadap Produktivitas Pekerja.

\section{UCAPAN TERIMA KASIH}

Penelitian ini dapat dilaksanakan dengan baik berkat bantuan dari berbagai pihak, untuk itu penulis mengucapkan terima kasih kepada KEMENRISTEKDIKTI atas bantuan dana hibah penelitian, pemilik perusahaan genteng press di Kabupaten Pringsewu dan segenap pihak yang membantu dalam kelancaran penelitian ini. 


\section{DAFTAR PUSTAKA}

[1] Wignjosoebroto, S., dkk. (2010). Kajian Ergonomi dalam Perancangan Alat Bantu Proses Penyetelan dan Pengelasan Produk Tangki Travo. Surabaya:Istitut Teknologi Surabaya.

[2] Nurulloh, M. 2013. Pengaruh Lingkungan Kerja Terhadap Produktivitas Pegawai Dinas Pekerjaan Umum Provinsi Kalimantan Timur. EKONOMIA 2. 1, 297-306.

[3] Geng Y., Ji W., Lin B., Zhu Y., 2017. The Impact of thermal environment on occupant IEQ perception and productivity. Building and Environment. 2017;121:158-67

[4] Mamahit, JM., Priscilia., et. al. 2016. Hubungan Antara Iklim Kerja Dengan Produktivitas Kerja Pada Tenaga Kerja Di PT. Tropica Cocoprima Desa Lelema Kecamatan Tumpaan Kabupaten Minahasa Selatan. Jurnal Ilmiah Farmasi 5. 1, 355-361.

[5] Tsutsumi, H., et. al. 2007. Effect of humidity on human comfort and productivity after step changes from warm an humid environment. Journal Building and Environment 42. 12, 4034-4042.

[6] Purnomo, Hari., dkk. 2000. Pengaruh Kelembaban, Temperatur Udara dan Bebean Kerja Terhadap Kondisi Faal Tubuh Manusia. Jurnal Logika 4. 5, 35-47.

[7] BPS Pringsewu. (2018). Pringsewu Dalam Angka. Pringsewu. Jaya Wijaya.

[8] Keputusan Menteri Kesehatan Republik Indonesia No. 1405. 2002. Persyaratan Kesehatan Lingkungan Kerja PErkantoran dan Industri. 